\title{
Challenges of Valproate Treatment During Pregnancy: Pros and Cons
}

\begin{abstract}
ANCA-ADRIANA ARBUNE ${ }^{1,2}$, DANA CRAIU ${ }^{1,3}$, IULIAN DAN CUCIUREANU ${ }^{4}$, CONSTANTIN IULIAN ${ }^{5 *}$, LILIANA LĂCRĂMIOARA PAVEL ${ }^{5}$, ION SORIN BERBECE ${ }^{5}$, CAMELIA ANA GRIGORE ${ }^{5}$, ADRIANA DULAMEA ${ }^{1,2}$

${ }^{1}$ Carol Davila University of Medicine and Pharmacy, 37 Dionisie Lupu Str., 4192910, Bucharest, Romania

${ }^{2}$ FundeniClinical Institute, Neurology Clinic, 258 Fundeni Road, 022322, Bucharest, Romania

${ }^{3}$ Clinical Hospital "Prof. Dr. AlexandruObregia", 10 Berceni Road, 041914, Bucharest, Romania

${ }^{4}$ Grigore T. Popa University of Medicine and Pharmacy, Faculty of Medicine, III-rd Medical Department, 16 Universitatii Str., 700115 , Iasi, Romania

${ }^{5}$ Dunarea de Jos, University of Medicine and Pharmacy, 47 Domneasca Str., 800008, Galati, Romania

Valproic acid and its salt, sodium valproate, are an effective treatment for epilepsy, the most common chronic neurologic disorder worldwide. Teratogenic associations reported after embryofetal exposure has limited the recommendations of valproate use in women of childbearing age, after careful evaluation of the benefits and risks of this medication. The mechanisms of valproate damage during pregnancy are complex and incompletely clarified up to date. Maternal and fetal impact of valproate is a critical issue, standing at the base of the new consensus on practical guidelines for clinical use of antiepileptic treatment in fertile women.
\end{abstract}

Keywords: pregnancy, epilepsy, Valproate

The anticonvulsant effect of valproic acid was discovered accidentally in 1967 by Meunier and Carraz, in the course of testing other antiepileptic drugs [1,2], although valproic acid was synthesized since 1882 [3]. An equimolecular combination of valproic acid and its salt, sodium valproate, has been used for the treatment of epilepsy in the United States of America since 1983 [4]. Nevertheless, the alert of birth defects related to valproate use during pregnancy emerged only in the early 1980s [5].

Valproic acid is 2 propyl-pentanoic acid, a branched chain organic acid that is converted to valproate ion, as the active form in the blood (Figure1). The antiepileptic activity of this small monocarboxylic acid is attributed to the $\mathrm{C}=\mathrm{O}$ bonding, that presents electrostatic interaction with the target protein [6].

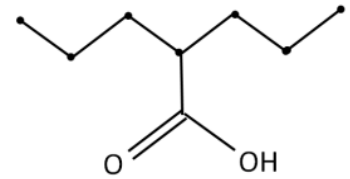

Fig.1. The chemical structure of valproic acid: 2 propylpentanoic acid $\left(\mathrm{C}_{8} \mathrm{H}_{15} \mathrm{O}_{2}\right)[7]$

Valproic acid and the derivates of sodium-valproate are used worldwide for the treatment of epilepsy and have been proved effective for the control of a broad spectrum of types of epileptic seizures, either in monotherapy or added to other antiepileptic drugs. Valproate (VAP) is indicated for generalized epilepsy, childhood absence epilepsy, juvenile myoclonic epilepsy or status epilepticus, and additionally for migraine prophylaxis, bipolar disorder - acute mania and/or mixed episodes. It is also an alternative treatment option to anxiolytic or antidepressant disorders, aggressive behavior and persistent impulsivity [8].

\section{Theories of Valproate Teratogenicity}

Valproate determines the increase of gamma-aminobutyric acid (GABA) concentration in the brain, either by enhancing the synthesis, or by inhibiting the enzymatic catabolism. It also induces a membrane stabilizing effect by blocking voltage-gated sodium channels [9]. Nevertheless, the exact mechanism of action of VPA is still not fully understood.

\footnotetext{
*email: drconstantiniulian@gmail
} 
Considering the safety during pregnancy, VPA is classified as D class, meaning a high-risk drug. There are a few proposed mechanisms to explain the teratogenicity of VPA. Valproate can cross the placenta and accumulatesin high concentrationsin the embryonic circulation, increasing the risk of toxicity and teratogenity [10]. The transfer of VPA across the placenta is influenced by the transporter proteins of monocarboxylic acid [11]. The differences in VPA pharmacokinetics and pharmacodynamics are explained by the genetic variation of transporter proteins and the occurrence of specific mutations, particularly the C3435T mutation. The oxidative stress was confirmed as teratogenic mechanism: the VPA anion in the blood, by possible bounding to the antioxidant enzymes, impairssuperoxide detoxification and determines embryofetal alterations. Due to the known detrimental effects of folate deficiency on embryo development, many studies focused on folate antagonism of VPA, that is known to interact with multiple targets, not only folate [12].

\section{Results and discussions \\ Epilepsy and Fertility}

The seizures have a direct effect on fertility by decreasing the libido, increasing the rate of menstrual cycle abnormalities to $33 \%$ in comparison with $12-14 \%$ in the general population, and increasing the rate of polycystic ovaries to $10-25 \%$ in comparison with $4-7 \%$ in the general population [13]. Other factors which can influence fertility of women with epilepsy are psychological status, social integration, the possibility of finding a partner and frequency of unprotected sexual contacts. The proposed mechanism to explain these dysfunctions is related to the abnormal secretion of follicle stimulating and luteinizing hormones (FSH and LH) following the interaction between the epileptogenic amygdala and hypothalamus, resulting in disruption of the production of gonadotrophin releasing hormone (GnRh) from the hypothalamic preoptic area during temporal mesial seizures [14]. Moreover, VPA interferes with sex hormone levels by increasing free and total testosterone, dehydro-epiandrostendione, $\Delta 4$-Androstendione, free androgen index, $\mathrm{LH} / \mathrm{FSH}$ ratio (luteal phase) and decreasing estradiol (follicular phase) [15].

Many antiepileptic drugs are related to contraceptive failure and are classified in three categories: knowing to cause contraceptive failure, causing contraceptive failure at high doses and with no known effect on contraceptive failure, VPA being included in the last category[14].

\section{Impact of Valproate during Pregnancy}

Special considerations are required for VPA during the pregnancy due to the pharmacokinetic changes, involving the alteration in absorption, volume distribution, increased metabolic rate and renal excretion [16] secondary to normal pregnancy physiology. Increased plasma volume and concomitant decrease of drug-binding plasma proteins are observed in the first and second trimesters of pregnancy. The activity of the main liver enzymes is progressively modified from the beginning to the end of pregnancy, by increasing CYP2D6, CYP2E1, UGT1A4, CYP2C9, CYP3A4 or decreasing CYP1A2, CYP2C19 and CYP2N6, thus explaining the widechanges in antiepileptic drugs' metabolism. The variation in kidney function and body composition, especially in the percentages of fat mass, body water and body weight, depend on the age of pregnancy. Overall, the VPA levels fall, with a decrease in serum concentration up to 28\% [16].

The risk of seizures is increased during pregnancy, either general risks or related directly to seizures. General risks are the premature birth, small for date, low birth weight, cognitive impairment, especially in women with generalized seizures, although the occurrence of other complications during pregnancy or at birth are commonly expected. Seizures directly impact the pregnancy by fetal hypoxia or acidosis, low blood flow to the placenta, preeclampsia, miscarriage, deceleration of fetal heart rate and direct trauma of mother or baby $[17,18]$.

\section{Consequences of Perinatal Exposure to Valproate}

A large study on over one thousand pregnant women with epileptic seizures from Taiwan in comparison with the general population, found increased ratesof babies' abnormal events, such as 1.36 fold increase in low birth weight, 1.63 fold increase in preterm delivery and 1.37 fold increase in small for gestational age [19].

The most frequent effects of VPA exposure during pregnancy in comparison with unexposed individuals are: neural tube defects, facial cleft, hypospadias, cardiac defects, spina bifida or reduced cognitive outcomes related to specific deficits in verbal skills, language impairment, poorer levels of daily living skills, increased prevalence of autism spectrum disorder and 8-10 points lower intelligence quotient (IQ). Breast feeding infants of mothers treated with VPA need precautious, considering the concentrations of drug excreted in human milk range between $1 \%$ and $10 \%$ of serum levels, which were related to a higher risk of hematological disorders in infants [20]. 
A prospective observational study was conducted on children from birth to the age of 6 years (NEAD study), performing the assessment of cognitive consequences of fetal exposure to antiepileptic drugs. Mean IQ scores were adjusted for dose of antiepileptic drug, gestational age at birth, maternal IQ and periconceptional levels of folate. The lowest adjusted IQ scores were found for VPA (98), in comparison with Carbamazepine (106), Lamotrigine (110) and Phenytoin (105) [21].

Valproate is the most unsafe antiepileptic drug for pregnancy, according to the main pregnancy registries of women with epilepsy: North American Antiepileptic Drug Pregnancy Registry (NAAPR), UK Epilepsy and Pregnancy Register and European Registry of Antiepileptic Drugs and Pregnancy (EURAP). According to the latest EURAP report, the prevalence of major congenital malformation events associated to 1000-3000 mg/day of VAP exposure was $10.3 \%$, that means a higher rate than other antiepileptic drugs, such as Levetiracetam (2.8\%), Lamotrigine (2.9\%), Carbamazepine (5.5\%), Phenytoin $(6.4 \%)$.

Furthermore, the prevalence of major congenital malformation events after VPA exposure is directly proportional increased with the administered dose: $6.3 \%$ corresponding to a dose under $650 \mathrm{mg} /$ day, $11.3 \%$ corresponding to doses between 650 and $1450 \mathrm{mg} / \mathrm{day}$, and $25.2 \%$, corresponding to doses over $1450 \mathrm{mg} / \mathrm{day}$ [22].

Fetal VPA spectrum disorder is defined by documented exposure to VPA during pregnancy and the adjoining of specific major and minor malformations, such as dysmorphic face, with broad nasal bridge, short nose with forwardfacing nostrils, small mouth with thin upper lip and everted lower lip, ridging of the metopic suture, epicanthic folds, neatly arched eyebrows. The criteria for evaluation of fetal Valproate spectrum disorder are classified as essential, suggestive and supportive. The diagnosis requiresat least one essential criteria and at least two suggestive criteria or one suggestive and an additional supportive score over 3 points $[8,26,27]$.

\title{
Balanced Recommendations of Valproate
}

European Medicines Agency recommends avoiding VPA exposure during pregnancy by avoiding VPA as treatment for migraine, bipolar disorder, but also epilepsy, unless there is no other effective treatment available. Therefore, any fertile girl or woman should not take VPA if she is not enrolled in a pregnancy prevention program.

However, if girls and women are treated with VPA, they should not stop taking medication without their doctor's guidance [23]. It has been documented that changing VPA with other antiepileptic drugsshortly before or during pregnancy in women with good seizure control under VPA treatment may result in status epilepticus. Thus, the decision to treat a woman with VPA should be balanced between the benefit to risk associated with intrauterine exposure [24].

The risk of having seizures with impact on fetal development, even after VPA change, persists. The prediction of seizures in pregnant women with epilepsy is therefore useful for the treatment alteration decisions. Currently, a prognostic model based on a nomogram (EMPiRE) analyze, was developed considering the gestational age, age at first seizure, learning difficulties, type and frequency of seizures, hospitalization for seizures before pregnancy, baseline dose of Lamotrigine or Levetiracetam [25], as VPA is discouraged as treatment during pregnancy.

The consensus statement from the European Reference Network for Congenital Malformations and Intellectual Disability for women taking VPA during pregnancy recommend a few actions to reduce the impact of VPA on fetal development. These measures include using the lowest effective dose, preferable prolonged release formulation, providing high levels of folate supplementation, offering targeted prenatal diagnostic testing for fetal defects and monitoring the clotting parameters in the mother and the neonate [8].

\section{Conclusions}

The management of epilepsy in fertile women is a continuous challenge. Teratogenicity is the main precaution for the practical use of Valproate, despite the efficient control of specific types of seizures. The recommendation of Valproate treatment must be based on sharing the decision with the informed patient and must balance the efficacy against the potential harms.

Improvement in the quality of life of women with epilepsy at a fertile age is expected by the development of new antiepileptic drugs, with lesser teratogenic consequences and good seizure control effects.

\author{
References \\ 1.MEUNIER, H., CARRAZ, G., MEUNIER, Y., EYMARD, P.,AIMARD, M., Therapie, 18, 1963, p. 435. \\ 2.CARRAZ, G., FAU, R., CHATEAU, R., BONNIN, J., Ann. Med. Psychol. (Paris), 122, 1964, p. 577. \\ 3.BURTON, B.S., Am Chem J3, 1882, p. 385. \\ 4.LEMPÉRIÈRE, T., Encephale, 27, no.4, 2001, 365.
}

Rev. Chim. $\bullet 71 \bullet$ no. $2 \downarrow 2020 \bullet$ https://revistadechimie.ro 
5.DALENS, B., RAYNAUD, E.J., GAULME, J., J. Pediatr., 97, no.2, 1980, 332.

6.COMELLI, N.C., DUCHOWICZ, P.R., LOBAYAN, R.M., et al., Molecular Informatics, 31, 2012, p. 181.

7.***National Center for Biotechnology Information. PubChem Database. https://pubchem.ncbi.nlm.nih.gov/compound/Sodium-valproate (accessed on Nov. 23, 2019).

8.CLAYTON-SMITH, J., BROMLEY, R., DEAN, J. ET AL., Orphanet J. Rare Dis., 14, no.1, 2019, p. 180.

9.OWENS, M.J., NEMEROFF, C.B., Psychopharmacol. Bull., 37 Suppl 2, 2003, p. 17.

10.VAJDA, F., Dose issues in antiepileptic therapy, Journal of Clinical Neuroscience, 19, 2012, p. 1475.

11.UTOGUCHI, N., AUDUS, K.L., International Journal of Pharmaceutics, 195, 2000, p. 115.

12.LLOYD, K.A., Bioscience Horizons: The International Journal of Student Research, 6, 2013, p.1.

13.BAUER, J., COOPER-MAHKORN, D., International Review of Neurobiology, 83, 2008, p. 135.

14.SAZGAR, M., AAN Continuum Neurology, 25, no.2, 2019, p. 408.

15.MCAULEY, J.W., ANDERSON, G.D., ClinPharmacokinet., 41, no.8, 2002, p.559.

16.TOMSON, T., LANDMARK, C.J., BATTINO, D., Epilepsia, 54, no. 3, 2013, p. 405.

17.ALlOTEY, J., AROYO-MANZANO, D., LOPEZ, P., ET AL., Eur. J. Obstet. Gynecol. Reprod. Biol., 215,2017, p. 12.

18.HERNÁNDEZ-DÍAZ, S., MCELRATH, T.F., PENNELL, P.B, et al., Ann. Neurol., 82, 2017, p. 457.

19.HARDEN, C., Epilepsy Curr., 10, no. 2, 2010, p. 40.

20.VEIBY, G., BJORK, M., ENGELSEN, B.A., GILHUS, N.E., Seizure, 28, 2015, p. 57.

21.MEADOR, K.J., BAKER, G.A., BROWNING, N., et al., Lancet Neurol., 12, no. 3, 2013, p. 244.

2.TOMSON, T., BATTINO, D., BONIZZONI, E., et al., Lancet Neurol., 17, no. 6, 2018, p. 530.

23.SEN, A., NASHEF, L. Lancet, 392, no. 10146, p. 458.

24.MACFARLANE, A., GREENHALGH, T. BMC Pregnancy Childbirth.18, 2018, 200.

25.ALLOTEY, J., FERNANDEZ-FELIX, B.M., ZAMORA, J., MOSS, N., BAGARY, M., ET AL. PLOS Medicine, 165, no. 5, 2019 , p. e1002802. 26.CUCIUREANU, D.I., CONSTANTINESCU, I.M. , DANCIU, F., CUCIUREANU, T., EPILEPSIA, Volume: 56, Pages: 128-128, Supplement: 1, Special Issue: SI, Published: Feb 2015

27.CUCIUREANU, D.I., CUCIUREANU, T., CUCIUREANU, A., Conference: $23^{\text {rd }}$ World Congress of Neurology (WCN) Journal of the Neurological Sciences Volume: 381 Supplement: S Pages: 339-339 Meeting Abstract: 935, Published: Oct 152017

Manuscript received: 14.01 .2020 